\title{
Survival Trends in Elderly Patients with Glioblastoma in the United States: a Population-based Study
}

\author{
BINAY KUMAR SHAH ${ }^{1}$, AMIR BISTA $^{2}$ and SANDHYA SHARMA ${ }^{2}$ \\ ${ }^{1}$ Hematologist and Medical Oncologist, North Puget Cancer Center Sedro-Woolley, WA, U.S.A.; \\ ${ }^{2}$ Guthrie Robert Packer Hospital, Sayre, PA, U.S.A.
}

\begin{abstract}
Background/Aim: Concomitant and adjuvant temozolomide along with radiotherapy following surgery (the Stupp regimen) is the preferred therapy for young patients with glioblastoma as well as for elderly (>70 years) ones with favorable risk factors. This study investigated the survival trend since the introduction of the use of the Stupp regimen in elderly patients in a population-based setting. Materials and Methods: Surveillance, Epidemiology, and End Results 18 database was used to identify patients aged $\geq 70$ years with glioblastoma as the first primary cancer diagnosed from 1999 to 2010. Chisquare test, Kaplan-Meier analysis with log-rank test and Cox proportional hazard method were used for analysis. Result: A total of 5,575 patients were included in the survival analysis. Survival in Stupp era (year of diagnosis 22005) was significantly better compared to the pre-Stupp era with $p<0.001$ by log-rank test, with 1-, 2- and 3-year overall survival of $18.8 \%$ vs. $12.9 \%, 6.5 \%$ vs. $2.1 \%$ and $3.1 \%$ vs. $0.9 \%$ respectively, and hazard ratio for death in 3 years in the Stupp era was 0.87 (95\% confidence interval $=0.82-0.92 ; p<0.001)$ when compared with the pre-Stupp era. Factors such as younger age $(<85$ years), female sex, married status, Caucasian race and total resection favored better survival compared to their counterparts. Conclusion: This study shows that the survival of elderly patients with glioblastoma has improved since the introduction of the Stupp regimen. However, there are significant differences in survival rates among various cohorts.
\end{abstract}

Glioblastoma is the commonest primary brain tumor and accounts for $16 \%$ of all primary brain and CNS tumors and $45.2 \%$ of malignant primary brain and CNS tumors (1). Glioblastoma is the commonest glial tumor, accounting for

Correspondence to: Dr. Binay Kumar Shah, North Puget Cancer Center, 2000 Hospital Drive, Sedro-Woolley, WA 98284, U.S.A. Tel: +1 3608566021, Fax: +1 360856752, e-mail: binay.shah@gmail.com

Key Words: Glioblastoma, Stupp regimen, radiotherapy, SEER, survival. about $54 \%$ of all gliomas, with about three new cases per 100,000 populations per year $(1,2)$. It is also the most aggressive brain tumor with fewer than $10 \%$ of patients surviving beyond 5 years (3). Despite advances in therapy, none of the treatment modalities is curative.

Radiotherapy has demonstrated survival benefit in glioblastoma since the 1970s (4-6). In a randomized, multicenter phase III trial by The European Organisation for Research and Treatment of Cancer (EORTC), Brain Tumor and Radiotherapy Groups and the National Cancer Institute of Canada (NCIC) Clinical Trials Group, concomitant administration of temozolomide with fractionated radiotherapy followed by up to six cycles of adjuvant temozolomide was compared with RT alone in patients with newly diagnosed glioblastoma. A total of 573 patients were enrolled in the study. The median age at diagnosis was 56 years. The results of the study presented by Stupp et al. showed that the unadjusted hazard ratio for death in the radiotherapy-plus-temozolomide group compared to the radiotherapy group was 0.63 (95\% Confidence Interval $=0.52-0.75 ; p<0.001)$. The median survival of patients who received temozolomide and radiotherapy was 14.6 months compared to 12.1 months for the radiotherapy only group (7).

The Stupp regimen is widely used for the management of patients with glioblastoma. However, as far as we are aware, there are no data on survival of elderly patients in the preStupp and Stupp era. We conducted this population-based study to analyze survival patterns of such elderly patients.

\section{Materials and Methods}

Study population. We used Surveillance, Epidemiology, and End Results (SEER) 18 registries to select elderly patients ( $\geq 70$ years) with glioblastoma as first primary malignancy from January 1999 to December 2010. We excluded cases diagnosed from June 2004 (presentation of the study at the annual American Society of Clinical Oncology meeting) to March 2005 (date of publication of the Stupp et al. study) to minimize mixed practice patterns during that time period. We excluded patients diagnosed by death certificate or autopsy only, or those who were alive with no survival data. We excluded patients with unknown marital status, surgery NOS or local tumor 
Table I. Demographic distribution of patient population in the pre-Stupp and Stupp eras.

\begin{tabular}{|c|c|c|c|c|}
\hline Characteristic & Total, n (\%) & $\begin{array}{c}\text { Pre-Stupp } \\
(\mathrm{N}=2699), \mathrm{n}(\%)\end{array}$ & $\begin{array}{c}\text { Stupp } \\
(\mathrm{N}=3340), \mathrm{n}(\%)\end{array}$ & $p$-Value* \\
\hline Radiotherapy & & & & $<0.0001$ \\
\hline None & $2207(36.5)$ & $977(36.2)$ & $1230(36.8)$ & \\
\hline Beam RT/beam with other forms of RT & $3596(59.5)$ & 1585 (58.7) & $2011(60.2)$ & \\
\hline Other forms of RT & $62(1.0)$ & $32(1.2)$ & $30(0.9)$ & \\
\hline Unknown & $174(2.9)$ & $105(3.9)$ & $69(2.1)$ & \\
\hline Surgery & & & & 0.011 \\
\hline None & $1710(28.3)$ & $819(30.3)$ & $891(26.7)$ & \\
\hline Partial resection & $2729(45.2)$ & $1208(44.8)$ & $1521(45.5)$ & \\
\hline Total resection & $1523(25.2)$ & $639(23.7)$ & $884(26.5)$ & \\
\hline Surgery NOS/local tumor destruction & $56(0.9)$ & $26(1.0)$ & $30(0.9)$ & \\
\hline Unknown & $21(0.3)$ & $7(0.3)$ & $14(0.4)$ & \\
\hline Marital status & & & & 0.408 \\
\hline Married & $3652(60.5)$ & $1622(60.1)$ & $2030(60.8)$ & \\
\hline Single & $395(6.5)$ & $169(6.3)$ & $226(6.8)$ & \\
\hline $\mathrm{S} / \mathrm{D} / \mathrm{W}$ & $1812(30.0)$ & $818(30.3)$ & $994(29.8)$ & \\
\hline Unknown & $180(3.0)$ & $90(3.3)$ & $90(2.7)$ & \\
\hline Age & & & & 0.079 \\
\hline 70 to $<85$ years & $5627(93.2)$ & $2532(93.8)$ & 3095 (92.7) & \\
\hline $85+$ years & $412(6.8)$ & 197 & & \\
\hline Race & & & & 0.174 \\
\hline White & $5586(92.5)$ & 2515 (93.2) & 3071 (91.9) & \\
\hline Black & $235(3.9)$ & $95(3.5)$ & $140(4.2)$ & \\
\hline Other & $212(3.5)$ & $85(3.1)$ & $127(3.8)$ & \\
\hline Unknown & $6(0.1)$ & $4(0.1)$ & $2(0.1)$ & \\
\hline Gender & & & & 0.575 \\
\hline Male & $3153(52.2)$ & $1420(52.6)$ & $1733(51.9)$ & \\
\hline Female & $2886(47.8)$ & 1279 (47.4) & $1607(48.1)$ & \\
\hline
\end{tabular}

RT: Radiotherapy; NOS: Not otherwise specified; S/D/W: Single/divorced/widowed; *Chi-square test.

destruction only, or unknown surgical status, unknown radiation status or receipt of radiation other than beam radiation from the survival analysis. SEER 18 covers about $27.8 \%$ of total US population (8) and includes registries from Atlanta, Connecticut, Detroit, Hawaii, Iowa, New Mexico, San Francisco-Oakland, Seattle-Puget Sound, Utah, Los Angeles, San Jose-Monterey, Rural Georgia, the Alaska Native Tumor registry, Greater California, Kentucky, Louisiana, New Jersey and Greater Georgia. The SEER program maintains a case ascertainment of about $98 \%$ by conducting rigorous quality control studies every other year (9). We included patients diagnosed during January 1999 to May 2004 in the pre-Stupp era, and those diagnosed during April 2005 to December 2010 in the Stupp era.

Statistical methods. We compared the baseline characteristics of the patients using chi-square test and two-sided $p$-values. We analyzed overall survival using the Kaplan-Meier method and compared using two-sided long-rank statistics. We used Cox proportional-hazards model for multivariate analyses to compare survival in both eras. The patients were followed-up for 36 months or until December 2014.

\section{Results}

Study population. A total of 2,699 patients from the pre-Stupp era and 3340 cases from the Stupp era met the inclusion criteria. The baseline demographic and clinical characteristics of the study population are elaborated in Table I. The demographic characteristics including age group, race, sex and marital status were comparable in both groups. Receipt of radiotherapy and surgery (partial or complete resection) was significantly better in the Stupp era compared with the preStupp era.

Survival in the Stupp and pre-Stupp eras for the whole population. The median overall survival was 5 months for both groups but the overall survival rate was significantly better in the Stupp era compared to the pre-Stupp era $(p<0.001$ by logrank test; 1-, 2- and 3- year rates of $18.8 \% \mathrm{vs} .12 .9 \%, 6.5 \% \mathrm{vs}$. $2.1 \%$ and $3.1 \%$ vs. $0.9 \%$, respectively). The hazard ratio for death for the Stupp era compared to the pre-Stupp era was 0.86 (95\% confidence interval $=0.82-0.91, p<0.001)$ after adjusting for confounding variables such as extent of surgery, receipt of radiotherapy, age, sex, race and marital status (Figure 1).

Factors associated with survival in the Stupp and pre-Stupp eras. In the pre-Stupp era, those who were separated, divorced or widowed had significantly worse survival compared to married patients. Surgical resection (partial or complete) and receipt of radiotherapy were independent predictors of better 
Table II. Factors associated with survival in the pre-Stupp and Stupp eras.

\begin{tabular}{|c|c|c|c|c|}
\hline \multirow[t]{2}{*}{ Parameter } & \multicolumn{2}{|c|}{ Pre-Stupp era } & \multicolumn{2}{|c|}{ Stupp era } \\
\hline & Adjusted HR (95\% CI) & $p$-Value & Adjusted HR (95\% CI) & $p$-Value \\
\hline Age ( $\geq 85$ vs. $70-84$ years) & $1.15(0.98-1.36)$ & 0.10 & $1.26(1.1-1.45)$ & 0.001 \\
\hline Gender (female vs. male) & $0.97(0.89-1.05)$ & 0.44 & $0.9(0.83-0.97)$ & 0.005 \\
\hline \multicolumn{5}{|l|}{ Marital status } \\
\hline Married & Reference & & & \\
\hline Single & $1.02(0.86-1.20)$ & 0.84 & $1.18(1.02-1.36)$ & 0.003 \\
\hline $\mathrm{S} / \mathrm{D} / \mathrm{W}$ & $1.11(1.01-1.22)$ & 0.028 & $1.14(1.05-1.24)$ & 0.003 \\
\hline \multicolumn{5}{|l|}{ Race } \\
\hline Caucasian & Reference & & & \\
\hline African American & $1.04(0.84-1.3)$ & 0.71 & $1.05(0.87-1.26)$ & 0.62 \\
\hline Other & $0.83(0.66-1.05)$ & 0.12 & $0.75(0.62-0.91)$ & 0.003 \\
\hline \multicolumn{5}{|l|}{ Surgery } \\
\hline \multicolumn{5}{|l|}{ None } \\
\hline Partial resection & $0.65(0.59-0.71)$ & $<0.001$ & $0.65(0.59-0.71)$ & $<0.001$ \\
\hline Total resection & $0.54(0.48-0.61)$ & $<0.001$ & $0.48(0.43-0.53)$ & $<0.001$ \\
\hline RT vs. no RT & $0.44(0.40-0.48)$ & $<0.001$ & $0.38(0.25-0.41)$ & $<0.001$ \\
\hline
\end{tabular}

S/D/W: Single/divorced/widowed; HR: hazard ratio; CI: confidence interval; RT: radiotherapy.

survival in both eras. Younger age, female sex, married status and Caucasian race were independent predictors of superior survival in the Stupp era (Table II).

\section{Discussion}

In Western countries, life expectancy has been increasing. Life expectancy at birth in developed countries now ranges from 76 to 80 years (10) and is estimated to reach 88.8 years for women and 85 years for men in 2050 (11). Glioblastoma is primarily a disease of the elderly, with median age at diagnosis of 64 years (12). The incidence of glioblastoma gradually rises with increasing age and peaks at 75 to 84 years of age (13). With a growing and aging U.S. population, the number of cases of glioblastoma is expected to increase.

The National Comprehensive Cancer Network recommends standard focal brain concurrent chemoradio-therapy with temozolomide followed by adjuvant therapy with temozolomide for elderly patients ( $>70$ years) with good performance status. This recommendation is based on the improvement in survival rates with therapy among younger patients treated with the Stupp regimen (7). Our study showed that the survival of elderly patients ( $\geq 70$ years) has improved in the Stupp era (with $14 \%$ reduction in the relative risk of death). The timing in the survival improvement suggests that change in the practice pattern with adoption of the Stupp regimen for treatment of patients with glioblastoma led to the improvement in survival. The survival rates in our study in the Stupp era are lower than those observed in the EORTC/NCIC study. There are several possible explanations for this. Older patients in our study represent real-world patients with several comorbidities.

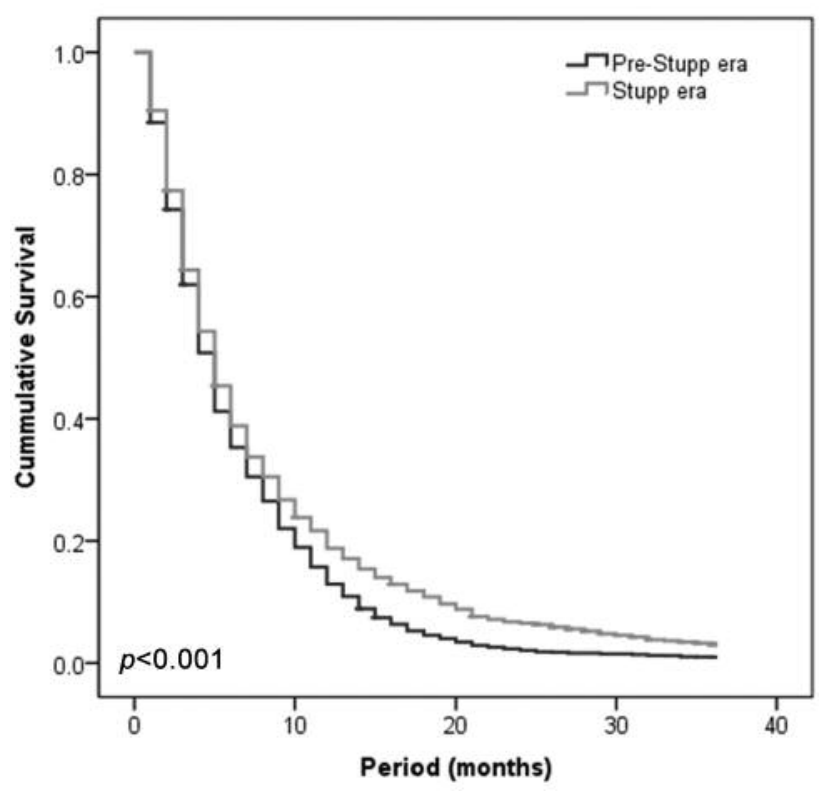

Figure 1. Overall survival in pre-Stupp era and Stupp era by KaplanMeier curve.

Moreover, a proportion of patients in our study may not have received radiotherapy-plus-temozolomide therapy.

Female sex was an independent predictor of better survival. Although unclear, this may be because of factors such as better compliance rates among female patients, and differences in drug metabolism. More research is needed to find out why survival is better among females compared to males. Superior survival among married patients suggests the role of social 
support in management of patients with cancer. Several studies have reported ethnic differences in cancer outcomes (14-17). Survival differences by ethnicity may be secondary to differences in access to care, or comorbidities, or other socioeconomic factors. An important review by Shavers et al. did not reveal any significant ethnic differences in the effectiveness of treatment of cancer (18). Clearly, this area needs more research to evaluate factors including possible differences in disease biology and differences in drug metabolism that may be responsible for ethnic disparities in survival of patients with glioblastoma.

The strengths of our study include a large sample size, as well as a long-term follow-up of patients. Limitations of the study include lack of information of chemotherapy used. Furthermore, individual-level data on socioeconomic status were not available. Therefore, the conclusions of this study are based on the assumption of a changing pattern of treatment of glioblastoma since the results of treatment with the Stupp regimen became available.

\section{Funding}

None.

\section{References}

1 Ostrom QT, Gittleman H, Farah P, Ondracek A, Chen Y, Wolinsky Y, Stroup NE, Kruchko C and Barnholtz-Sloan JS: CBTRUS statistical report: primary brain and central nervous system tumors diagnosed in the United States in 2006-2010. Neuro Oncol 15(Suppl 2): ii1-56, 2013.

2 Ostrom QT, Gittleman H, Fulop J, Liu M, Blanda R, Kromer C, Wolinsky Y, Kruchko C and Barnholtz-Sloan JS: CBTRUS Statistical Report: Primary brain and central nervous system tumors diagnosed in the United States in 2008-2012. Neuro Oncol 17(Suppl 4): iv1-iv62, 2015.

3 Stupp R, Hegi ME, Mason WP, van den Bent MJ, Taphoorn MJ, Janzer RC, Ludwin SK, Allgeier A, Fisher B, Belanger K, Hau P, Brandes AA, Gijtenbeek J, Marosi C, Vecht CJ, Mokhtari K, Wesseling P, Villa S, Eisenhauer E, Gorlia T, Weller M, Lacombe D, Cairncross JG, Mirimanoff RO; European Organisation for Research and Treatment of Cancer Brain Tumour and Radiation Oncology Groups; National Cancer Institute of Canada Clinical Trials Group: Effects of radiotherapy with concomitant and adjuvant temozolomide versus radiotherapy alone on survival in glioblastoma in a randomised phase III study: 5-year analysis of the EORTC-NCIC trial. Lancet Oncol 10(5): 459-466, 2009.

4 Walker MD, Green SB, Byar DP, Alexander E Jr., Batzdorf U, Brooks WH, Hunt WE, MacCarty CS, Mahaley MS Jr., Mealey J Jr., Owens G, Ransohoff J 2nd, Robertson JT, Shapiro WR, Smith KR Jr., Wilson $\mathrm{CB}$ and Strike TA: Randomized comparisons of radiotherapy and nitrosoureas for the treatment of malignant glioma after surgery. N Engl J Med 303(23): 13231329,1980

5 Andersen AP: Postoperative irradiation of glioblastomas. Results in a randomized series. Acta Radiol Oncol Radiat Phys Biol 17(6): 475-484, 1978.
6 Walker MD, Alexander E Jr., Hunt WE, MacCarty CS, Mahaley MS Jr., Mealey J Jr., Norrell HA, Owens G, Ransohoff J, Wilson CB, Gehan EA and Strike TA.: Evaluation of BCNU and/or radiotherapy in the treatment of anaplastic gliomas. A cooperative clinical trial. J Neurosurg 49(3): 333-343, 1978.

7 Stupp R, Mason WP, van den Bent MJ, Weller M, Fisher B, Taphoorn MJ, Belanger K, Brandes AA, Marosi C, Bogdahn U, Curschmann J, Janzer RC, Ludwin SK, Gorlia T, Allgeier A, Lacombe D, Cairncross JG, Eisenhauer E and Mirimanoff RO; European Organisation for Research and Treatment of Cancer Brain Tumor and Radiotherapy Groups; National Cancer Institute of Canada Clinical Trials Group: Radiotherapy plus concomitant and adjuvant temozolomide for glioblastoma. N Engl J Med 352(10): 987-996, 2005.

8 National Cancer Institute (2012) Incidence - SEER 18 regs research data _ hurricane Katrinaimpacted Louisiana cases. http://seer. cancer.gov/data/seerstat/nov2012/. Accessed 30 March 2016

9 National Cancer Institute, Surveillance Systems Branch (2013) Surveillance, epidemiology and end result. http://seer.cancer.gov/ data/metadata.html\#2. Accessed 30 March 2016.

10 Kinsella K and Velkoff V: An Aging World: 2001. U.S. Census Bureau, Washington, DC: U.S. Government Printing Office. Series P95/01-1, 2001.

11 Bohk C and Rau R: Changing Mortality Patterns and Their Predictability: The case of the United States. Dynamic Demographic Analysis. pp 69-89, 2016. Springer International Publishing Switzerland. Doi:10.1007/978-3-319-26603-9_5

12 Chakrabarti I, Cockburn M, Cozen W, Wang YP and PrestonMartin S: A population-based description of glioblastoma multiforme in Los Angeles County, 1974-1999. Cancer 104(12): 2798-806, 2005.

13 Ostrom QT, Gittleman H, Farah P, Ondracek A, Chen Y, Wolinsky Y, Stroup NE, Kruchko C and Barnholtz-Sloan JS: CBTRUS statistical report: Primary brain and central nervous system tumors diagnosed in the United States in 2006-2010. Neuro Oncol 16(5): 760, 2013.

14 Eley JW, Hill HA, Chen VW, Austin DF, Wesley MN, Muss HB, Greenberg RS, Coates RJ, Correa P, Redmond CK, Hunter CP, Herman AA, Kurman R, Blacklow R, Shapiro S and Edwards BK: Racial differences in survival from breast cancer: results of the National Cancer Institute black/white cancer survival study. JAMA 272(12): 947-954, 1994.

$15 \mathrm{Li}$ CI, Malone KE and Daling JR: Differences in breast cancer stage, treatment, and survival by race and ethnicity. Arch Intern Med 163(1): 49-56, 2003.

16 Sanoff HK, Sargent DJ, Green EM, McLeod HL and Goldberg RM. Racial differences in advanced colorectal cancer outcomes and pharmacogenetics: A subgroup analysis of a large randomized clinical trial. JCO 27(25): 4109-4115, 2009.

17 Shah BK, Bista A and Shafii B (2015) Disparities in receipt of radiotherapy and survival by age, sex and ethnicity among patients with stage I diffuse large B-cell lymphoma. Leuk Lymphoma 56(4): 983-986, 2015.

18 Shavers VL and Brown ML. Racial and ethnic disparities in the receipt of cancer treatment. J Natl Cancer Inst 94(5): 334-357, 2002.

Received July 25, 2016

Revised August 3, 2016

Accepted August 5, 2016 